\title{
Sensing and Degradation of Chlorpyrifos by using Environmental Friendly Nano Materials
}

\author{
Hameed SW, Tahir MA, Kiran S, Ajmal S and Munawar A* \\ University of Veterinary and Animal Sciences, Lahore, Punjab, Pakistan
}

\begin{abstract}
The nanoparticles of gold and cadmium tellurium quantum dot (CdTe QD) are effective systems for the detection and quantitative removal of chlorpyrifos which is a commonly used pesticide found in surface water of developing nations. Gold nanoparticles coated with citrate changes its color from pink to purple in the presence of chlorpyrifos. Unique CdTe QDs were developed and functionalized by using glucose oxidase for detection of chlorpyrifos. Change in absorbance related to the change in $\mathrm{H}_{2} \mathrm{O}_{2}$ concentration. In the solution phase, chlorpyrifos adsorb onto the CdTe QDs surface. During this prolonged interaction, change in color takes place and adsorbed chlorpyrifos becomes precipitated. Thus complete removal of this chlorpyrifos occurs when contaminated water is passed over different CdTe QDs supported on some surface such as alumina. We believe that this method has great potential in the purification of drinking water using gold and CdTe QD nanoparticles.
\end{abstract}

Keywords: Cadmium Tellurium; Quantum Do; Chlorpyrifos; Gold nanoparticles

\section{Introduction}

In agriculture, farmers use several kinds of pesticides to protect seeds and crops before and after harvesting. Pesticide is a word used in wide sense for organic toxic compounds used to control bacteria, insects, weeds, rodents, nematodes and other pests. The pesticide residues are contaminating our environment and may enter into the food chain through water, air and soil. They affect our ecosystems and cause several health problems to humans and animals. Pesticides can be carcinogenic and have cytotoxic effects on humans. They can produce different kind of disorders such as multiple myeloma, nerve disorders, infertility, immunological and respiratory diseases. Detection of pesticides at the levels developed by the Environmental Protection Agency (EPA) still remains a challenge. Different chromatographic methods coupled to discriminatory detectors have been conventionally used for pesticide analysis due to their reliability, sensitivity and effectiveness [1]. Nevertheless, they are time-consuming, lengthy; require too much expensive equipments and highly-trained technicians. Over the past decade, significant attention has been given to the development of sensors for the detection of pesticides as a promising alternative. A sensor is a self-contained device that integrates an immobilized element (e.g. enzyme, pesticide, antibiotics, ascorbic acid, DNA probe and antibody) that can recognize the analyte (e.g. enzyme substrate, antigen and complementary DNA) and different transduction element [2]. The purpose of transduction element is used to convert the chemical signal resulting from the interaction of the analyte with the receptor into an electronic one. According to the signal transduction technique, sensors are classified into electrochemical, optical, piezoelectric and mechanical biosensors [3]. Electrochemical transducers have been widely used in sensors for pesticides detection due to their high sensitivity, their low cost, simple design and small size that make them excellent candidates for the development of portable sensors. According to the recognition element, enzymatic, whole cell, immunochemical, and DNA biosensors have been developed for different pesticides detection [4].

Environmental pollution and energy shortage are two current major global encounters faced by human beings. While in the past two decades, the evolution of nanotechnology represents an ever improving process in the design, discovery, novel utilization, and creation of artificial nano scale materials [5]. To meet the major challenges in environmental sustainability, these nanomaterials are stimulating various important practical applications in the environmental sector. The rapid development in nanomaterials and catalysis science has led to significant advances in understanding of the nanoparticles. The morphology, fabrication, and modification of novel nanomaterials allow for enhanced performance for environmental related applications [6].

The emerging synergy between nanotechnology and sensors has been exploited over the past few years. Serious research efforts have been performed for the design of efficient nanomaterial based sensors that exhibit high sensitivity, specificity, ageing, repeatability and stability. The immobilization of nanomaterials onto sensing devices generates novel interfaces that enable the sensitive electrochemical or optical detection of analytes. In few cases, nanomaterials have been used as labels to amplify the signal measured [7].

The US department of Environmental Protection Agency (EPA) defines the term pesticide as any substance or mixture of substances intended for avoiding, destroying, preventing, or modifying any pest. From these definitions, it is clear that the term "pesticide" not only states to insecticides, but it also applies to herbicides, fungicides, and various other substances used to control pests. Pesticides are widely used in our environments (e.g., agriculture, homes, gardens, and veterinary medicine) to control pests. While their application is beneficial, there are serious risks, to both human health and the environmental, associated with their use.

Among the class of pesticides, organophosphate pesticides (OPs) such as parathion, chlorpyrifos and malathion are the most widely used chemical pesticides throughout the world. When pesticide solutions are

*Corresponding author: Anam Munawar, University of Veterinary and Animal Sciences Lahore, Punjab, Pakistan, Tel: +92 42 99212865; E-mail: anammunwar22@gmail.com

Received December 11, 2015; Accepted January 20, 2016; Published January 27,2016

Citation: Hameed SW, Tahir MA, Kiran S, Ajmal S, Munawar A (2016) Sensing and Degradation of Chlorpyrifos by using Environmental Friendly Nano Materials. J Biosens Bioelectron 7: 198. doi:10.4172/2155-6210.1000198

Copyright: (c) 2016 Hameed SW, et al. This is an open-access article distributed under the terms of the Creative Commons Attribution License, which permits unrestricted use, distribution, and reproduction in any medium, provided the original author and source are credited. 
sprayed, the nozzles on the equipments produce droplets. Some of these droplets are very small. Therefore, they remain suspended in air and are carried by air currents to other locations, potentially contaminating areas beyond the intended application sites. Furthermore, pesticides may threaten nearby wildlife when they are applied to crops by escaping into the atmosphere and being blown by winds to nearby areas [8]

Various sensor technology platforms can be used to probe the changes induced by the interaction of analyte molecules with the recognition element. These include resistive devices, capacitive devices, optical devices, micro-cantilever devices, and acoustic wave devices [9].

This research study will involve the synthesis of advanced innovative nanomaterials using chlorpyrifos as a goal analyte. Their potential use will be in the environmental monitoring and remediation. At first soil and water samples will be analysed for sensing and methodology will be extended to formulate remediation and treatment.

Main focus of this project was to address environment contamination and human health affected due to the residues of chlorpyrifos pesticide. Chlorpyrifos residues are most persistent pesticide in environment and cause neurological problems in human beings as well as in animals.

\section{Novelty statement}

Novelty statement of this research project is:

- Sensing / detection of organophosphate pesticide residues in different samples of soil and water.

- Removal of organophosphate residues by physical adsorption.

- Degradation of organophosphate residues in to less toxic or nontoxic end product.

- To evaluate the risk to ecosystem from organophosphate residues.

- To develop alternative nanomaterials, to reduce the usage of pesticides, and to reduce hazardous health effects on living organisms.

\section{Materials and Methods}

Project is divided in to three parts that are given below:

- $\quad$ Sensing

- Degradation

- $\quad$ Treatment

Nanoparticles were developed for sensing, degradation and absorbance of degraded product.

\section{Sampling}

Different soil and water samples were collected from those areas where chlorpyrifos was used frequently. Now these samples were analyzed for sensing and degradation.

\section{Analysis of soil and water samples}

Gold Nanoparticles complexation with chlorpyrifos pesticides in presence of $\mathrm{NaCl}$ was studied by using real water and soil samples. These samples were collected from industrial areas and areas where chlorpyrifos pesticide spray was used. Spectrophotometric analysis was done.

\section{Development of sensor}

Different metallic nanoparticles especially gold nanoparticles gain much attention due to their huge applications in sensors development. Gold nanoparticles coated with citrate changes its color from pink to purple in the presence of chlorpyrifos pesticide residues.

\section{Synthesis of gold nanoparticles}

Gold nano particles were synthesized by following Turkevich methodology. $5 \mathrm{~mL}$ of 3 molar Gold chloride solutions was diluted with $90 \mathrm{~mL}$ of double distilled water and heated until it begins to boil. To this $5 \mathrm{~mL}$ of $1 \mathrm{M}$ trisodium citrate solution was added and continued the reaction until the solution turned wine red. The purpose of trisodium citrate use was capping and reducing of synthesized nanoparticles [10]

\section{Preparation of CdTe QDs}

CdTe QDs was synthesized in the aqueous phase by two reaction steps. In first step, $0.0638 \mathrm{~g}$ of tellurium powder and $0.1 \mathrm{~g}$ of $\mathrm{NaBH}$ was added to $10 \mathrm{~mL}$ of distilled water under nitrogen atmosphere to form a black mixture, which was then stirred for $8 \mathrm{hrs}$. After the black color disappeared and white color was produced, the supernatant containing NaHTe was separated from the mixture and used as the precursor for the preparation of CdTe QDs. A $0.2284 \mathrm{~g}$ amount of $\mathrm{CdCl}_{2}$ and 210 $\mu \mathrm{L}$ of 3-mercaptopropionic acid (MPA) was dissolved in $125 \mathrm{~mL}$ of distilled water, and the $\mathrm{pH}$ value of the solution was then adjusted to 9 with $1.0 \mathrm{M} \mathrm{NaOH}$. The solution mixture was deoxygenated by using nitrogen for at least $30 \mathrm{~min}$.

In second step, freshly prepared NaHTe solution was transferred into the above mixture under nitrogen atmosphere, and the CdTe precursor was instantly formed, color change was appeared from colorless to orange. The mixture was stirred for $20 \mathrm{~min}$ at room temperature; then refluxed to produce CdTe QDs with desired sizes by adjusting the refluxing time. Green and red fluorescent CdTe QDs was produced in the result of refluxing for 1 and $48 \mathrm{~h}$, respectively. The crude CdTe QD solution was purified by ultrafiltration to remove excessive thiols, free cadmium ions, and byproducts. The purified CdTe QDs was finally dissolved in water to form a stock solution for further usage. The concentration of CdTe QD solution was estimated to be around $30 \mu \mathrm{M}$ based on the band edge absorption [11].

\section{Surface functionalization}

Glucose oxidase enzyme was deposited on the surface of CdTe QDs by electrostatic interaction. Hydrogen peroxide produces in the result of oxidation of glucose. By which many surface changes produce to quench the fluorescence by CdTe QDs.

\section{Results and Discussion}

\section{Lateral flow assay}

Citrate coated gold nanoparticles change its color from pink to purple. Change in color indicates the presence of chlorpyrifos pesticide in samples while color intensity is an indication of analyte concentration (Figure 1).

\section{Interaction of CdTe QD with chlorpyrifos}

Electrostatic interaction take place between quantum dot and chlorpyrifos, $\mathrm{H}_{2} \mathrm{O}_{2}$ produce in result. $\mathrm{H}_{2} \mathrm{O}_{2}$ concentration work as an indicator, change in absorbance and intensity was due to chlorpyrifos which quenched the fluorescence of $\mathrm{CdTe}$ QDs. $\mathrm{H}_{2} \mathrm{O}_{2}$ produce due the reduction of glucose oxidase enzyme on the surface of CdTe QDs (Figure 2).

Surface of quantum dots was negatively charged and interact 


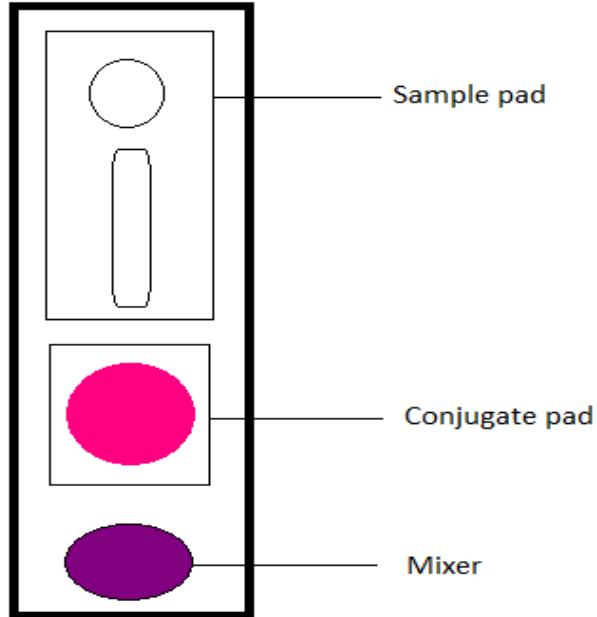

Figure 1: Lateral Flow for chlorpyrifos detection.

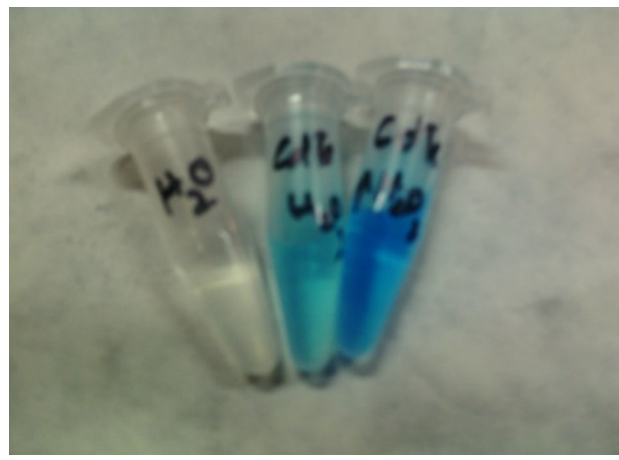

Figure 2: Change in color due to $\mathrm{H}_{2} \mathrm{O}_{2}$.

with positively charged chlorpyrifos particles. Due to the reduction of glucose oxidase fluorescence of quantum dots was quenched and decrease in intensity take place (Figure 3).

Absorbance analysis was performed and concluded photoluminescence of QDs was decreased due to the increase in concentration of chlorpyrifos (Figure 4).

This figure is depicting the change in intensity of fluorescence of cadmium tellurium quantum dots due to its surface modification. Quantum dots possess their own fluorescence due to their size, structure and chemical functionalities.

Cadmium tellurium interaction with chlorpyrifos results in degradation in to other components. These degraded forms of chlorpyrifos are considered less toxic as compare to whole component.

Organophosphate (OP) neurotoxins include an exceptional class of pollutants and chemical warfare (CW) agents which have a high severe toxicity. These organophosphates are strong inhibitors for esterase enzymes, such as neurotoxic esterase or acetyl- and butyl choline esterase. Simple methods such as fluorescence based assays for organophosphate (OP) neurotoxins detection have been developed. This type of detection is specific recognition by organophosphate hydrolase (OPH) enzyme. A unique biosensor has been reported for direct detection of OP neurotoxins for example paraoxon [12]. Change
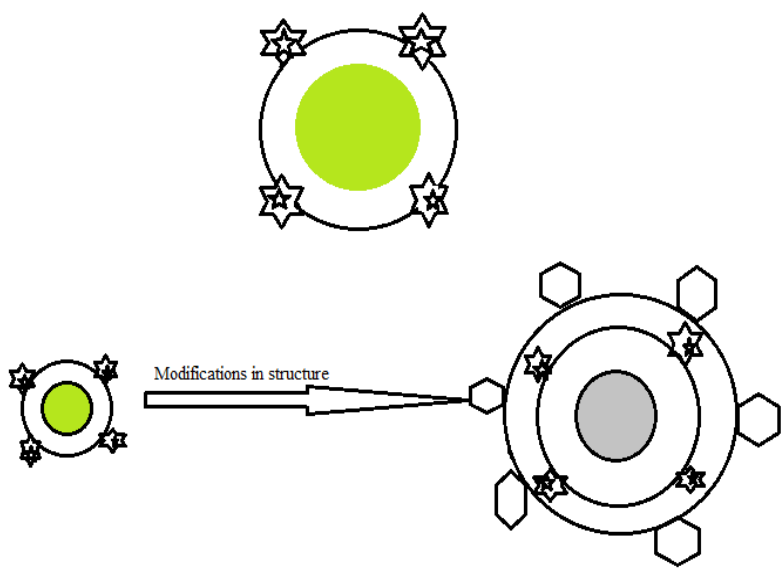

Figure 3: Mechanism of interaction of CdTe QDs.

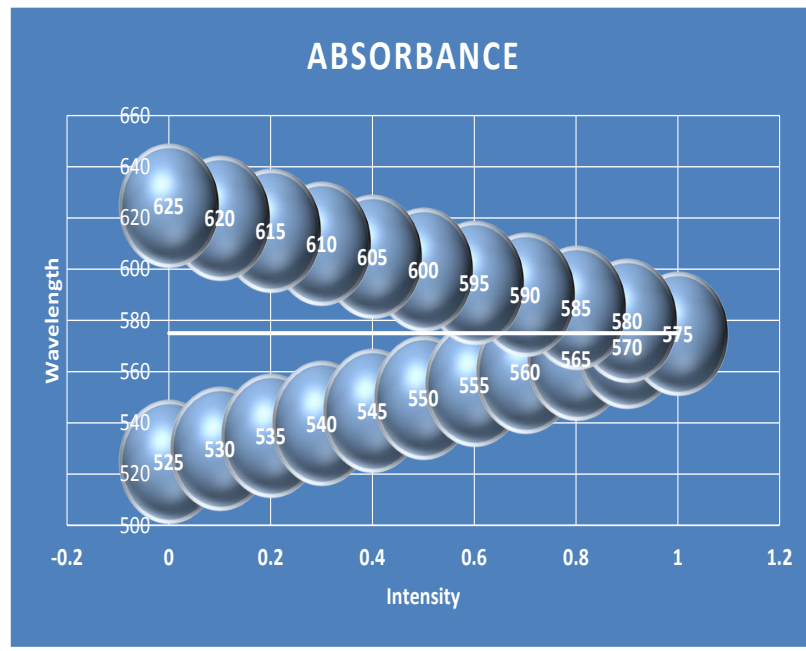

Figure 4: Decrease in intensity of CdTe QDs.

in fluorescence for organophosphate hydrolase (OPH) enzyme due to the displacement of competitive inhibitor by substrate for OPH enzyme is a base for biosensing by using fluorescence. Change in the intensity of fluorescence was directly related with concentration of paraoxon presented in the test solution. The sensitivity for the detection of paraoxon was obtained when OPH gold nanoparticle conjugates and enzyme inhibitor were presented in solution in equal concentration. Another study was reported for paraoxon detection based on biosensing by using QDs/OPH bioconjugate [13]. The (CdSe) ZnS core-shell QDs were reformed with OPH by using electrostatic interactions, due to the negatively charged QDs surfaces and the positively charged protein side chain (due to the presence of amine group NH2). Detection was based on quenching of photoluminescence (PL) of the OPH/QDs bioconjugate due to the presence of paraoxon. This result showed that the quenching of PL intensity was related to the conformational changes in the enzyme. Study was based on decrease in PL intensity of the OPH/QDs bioconjugate as the paraoxon concentration increases.

In a near recent, [14] have reported a biosensor for the analysis of the 2,4-dichlorophenoxyacetic acid based on competitive fluoro immunoassay by using CdTe QD. This herbicide can create severe 
Citation: Hameed SW, Tahir MA, Kiran S, Ajmal S, Munawar A (2016) Sensing and Degradation of Chlorpyrifos by using Environmental Friendly Nano Materials. J Biosens Bioelectron 7: 198. doi:10.4172/2155-6210.1000198

human health problems even at low concentration, that's why it is very important to develop a system for detection and quantification even at low levels for applications in food analysis. The reported fluoro immunoassay, contain an immune reactor column which has been chockfull by immobilizing anti-2,4- dichlorophenoxyacetic antibodies. By using this method it became possible to detect 2,4-D up to $250 \mathrm{pg}$ $\mathrm{mL} \_1$ in $50 \mathrm{mM}$ phosphate buffer solution ( $\mathrm{pH} 7.4$ ).

\section{Future Prospective}

In future analysis can be performed for the detection of degraded products either these degraded products are less harmful or not.

\section{References}

1. Yang GJ, Huang JL, Meng WJ, Shen M, Jiao XA (2009) A reusable capacitive immunosensor for detection of Salmonella spp. based on grafted ethylene diamine and self-assembled gold nanoparticle monolayers. Analytica chim acta 647: 159-166.

2. Gao X, Nie S (2003) Molecular profiling of single cells and tissue specimens with quantum dots. Trends in biotechnology 21: 371-373.

3. El-Boubbou K, Gruden C, Huang X (2007) Magnetic glyco-nanoparticles: a unique tool for rapid pathogen detection, decontamination, and strain differentiation. Journal of the American Chemical Society 129: 13392-13393.

4. Dzyadevych SV, Arkhypova VN, Soldatkin AP, Elskaya AV, Martelet C, et al. (2008) Amperometric enzyme biosensors: past, present and future. Irbm 29:171-180.

5. Delmulle BS, Saeger DSM, Sibanda L, Barna-Vetro I, Van Peteghem CH (2005) Development of an immunoassay-based lateral flow dipstick for the rapid detection of aflatoxin B1 in pig feed. Journal of agricultural and food chemistry 53: 3364-3368.
6. Kalele SA, Kundu AA, Gosavi SW, Deobagkar DN, Deobagkar DD, et al. (2006) Rapid Detection of Escherichia coli by Using Antibody-Conjugated Silver Nanoshells. Small 2: 335-338.

7. Kaur J, Singh KV, Boro R, Thampi K, Raje M, et al. (2007) Immunochromatographic dipstick assay format using gold nanoparticles labeled protein-hapten conjugate for the detection of atrazine. Environmental science \& technology 41: 5028-5036.

8. Patolsky F, Zheng G, Hayden O, Lakadamyali M, Zhuang X, et al. (2004) Electrical detection of single viruses. Proceedings of the National Academy of Sciences of the United States of America 101: 14017-14022.

9. Deo RP, Wang J, Block I, Mulchandani A, Joshi KA, et al. (2005) Determination of organophosphate pesticides at a carbon nanotube/organophosphorus hydrolase electrochemical biosensor. Analytica Chimica Acta 530: 185-189.

10. Kimling J, Maier M, Okenve B, Kotaidis V, Ballot H, et al. (2006) Turkevich method for gold nanoparticle synthesis revisited. The Journal of Physical Chemistry B 110: 15700-15707.

11. Li X, Zhou Y, Zheng Z, Yue X, Dai Z, et al. (2009) Glucose biosensor based on nanocomposite films of CdTe quantum dots and glucose oxidase. Langmuir 25: 6580-6586.

12. Simonian A, Good T, Wang SS, Wild J (2005) Nanoparticle-based optica biosensors for the direct detection of organophosphate chemical warfare agents and pesticides. Analytica chimica acta 534: 69-77.

13. Ji X, Zheng J, Xu J, Rastogi VK, Cheng TC, et al. (2005) (CdSe) ZnS quantum dots and organophosphorus hydrolase bioconjugate as biosensors for detection of paraoxon. The Journal of Physical Chemistry B 109: 3793-3799.

14. Vinayaka A, Basheer S, Thakur M (2009) Bioconjugation of CdTe quantum dot for the detection of 2,4-dichlorophenoxyacetic acid by competitive fluoroimmunoassay based biosensor. Biosensors and Bioelectronics 24: 1615 1620 . 